\section{Reforma Tributaria La adaptación de los contadores}

Las complejidades contenidas en la reforma redundan en un ejercicio de la profesión contable definitivamente desafiante; y no sólo por la gran carga de trabajo que tienen de enero a abril, sino por lo que representa el resto del año con las fiscalizaciones.
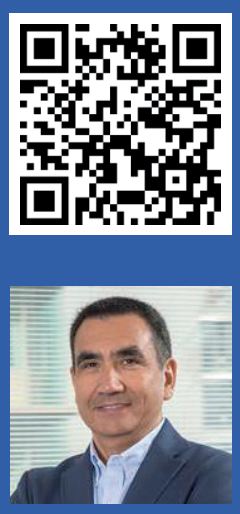

Escribe Manuel Mánquez Hatta Contador Público y Auditor, Universidad de Santiago Magíster en Planificación y Gestión Tributaria, Universidad de Santiago Socio, Mánquez Hatta Consultores Tributarios

Director Ejecutivo, Centro de Conocimiento Tributario

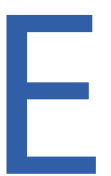
I presidente del Colegio de Contadores de Chile, Alejandro Vera, está preocupado; al igual que el gremio que lidera a nivel nacional. Este sentimiento, según lo ha explicado en diferentes medios de prensa se fue generado a medida que sus agremiados han ido avanzando en el estudio y dominio de la compleja Reforma Tributaria que se puso en marcha en septiembre del año 2014, y que fue modificada con la simplificación de ésta, en febrero de 2016.

Las proyecciones que hacen los contadores es que la Operación Renta del año tributario 2018 generará muchas diferencias de impuesto a pagar por los contribuyentes en fiscalizaciones posteriores y las correspondientes multas que eso conlleva.

Lo que ha ocurrido, es que las complejidades contenidas en la reforma redundan en un ejercicio de la profesión contable definitivamente desafiante; y no sólo por la gran carga de trabajo que representan los meses de enero a abril, sino por lo que representa el resto del año con las fiscalizaciones.

¿Pero cómo se llegó a este punto? Los tiempos han cambiado y las demandas sociales están más presentes, entonces se recurre a reformas tributarias que persiguen demasiados objetivos: recaudar, eliminar beneficios tributarios, crear otros nuevos, uniformar cargas impositivas, incluir normas que sólo apuntan a evitar la elusión; entre otras. Y el Servicio de Impuestos Internos (SII), también evolucionó, basando su labor en el análisis de la información por medios computacionales que orientan la fiscalización.

Efectivamente, la información que analiza la autoridad fiscal es reunida, procesada y clasificada -como el SII lo solicita- por los contadores, quienes deben entregarla en tiempo y forma como parte de la Operación Renta, y sujeto su incumplimiento generar multas que constituyen la base de conflictos con los clientes.

Sumada a esta labor recolectora de la información, los contadores deben determinar los impuestos de las empresas que atienden, lo que comienza por conocer y saber presentar más de 70 declaraciones juradas que contempla el menú actual, que incluye toda la información que el profesional utilizó como base para la determinación de los impuestos de sus clientes. Y a partir de esa misma información, procesada por el computador del SII, se generan múltiples supuestos de descuadraturas que son notificadas al contribuyente para que su contador vaya a aclararlas.

\section{EL COSTO DE LOS CAMBIOS}

El abanico de materias que debe dominar un contador en Chile no es menor: toda la técnica contable (recientemente modificada), los impuestos de las empresas, de sus dueños, de los trabajadores, normas laborales, la normativa previsional, cotizaciones de salud, licencias médicas, concurrir a las notificaciones de Tesorería, a las citaciones de la Dirección del Trabajo, patentes municipales y un largo etcétera. $Y$ pareciera ser que los gobiernos no han tomado conciencia del proceso de adaptación técnica que deben tener los contadores ante los cambios que se realizan en estos ámbitos.

Estas experiencias demuestran que los profesionales a cargo de la información contable y el cumplimiento tributario son fundamentales para la trasparencia de la información en el mercado y para la aplicación correcta de la normativa tributaria que finalmente se traduce en la recaudación base para financiar el gasto público. Tal vez es 
tiempo de revisar los contenidos de las materias que se incluyen en la formación de estos profesionales, los requisitos para su ejercicio profesional como acreditación de su conocimiento, dada la importancia que gradualmente han ido asumiendo en aspectos relevantes para el desarrollo de la economía del país.

\section{UNA VERDADERA REFORMA}

La Ley № 20.780 de 2014 -Reforma Tributaria- modificó tanto los impuestos que afectan a las empresas, como la manera de determinar varias de las rentas que deben declarar las personas naturales.

El régimen de las PYME's, el de las empresas familiares y la renta atribui$\mathrm{da}$, entre otros, son nuevas materias que los contadores tienen que incorporar a su background profesional; sumado al dominio que deben tener de los requisitos que permiten mantenerse o no en regímenes que estaban vigentes, y que ya no aplican para muchos contribuyentes.

Gran parte de la tributación de los agricultores, transportistas, rentistas de bienes raíces, venta de bienes inmuebles o inversiones acogidas al 57 bis, fueron modificadas y requieren no sólo que el contador domine sus requisitos y pormenores, sino que exigen además una inversión de tiempo relevante para explicárselas a los contribuyentes, ya que son ellos quienes finalmente deben decidir, entre todas las alternativas que dispone la ley, la modalidad con la cual se quieren afectar.

A modo de ejemplo, en la venta de bienes raíces, el contribuyente debe escoger -a lo menos- entre cuatro formas de cumplir su pago de impuestos por las ganancias que obtenga; lo que no es muy razonable al considerar que los contribuyentes no son expertos tributarios y que los contadores no pue-

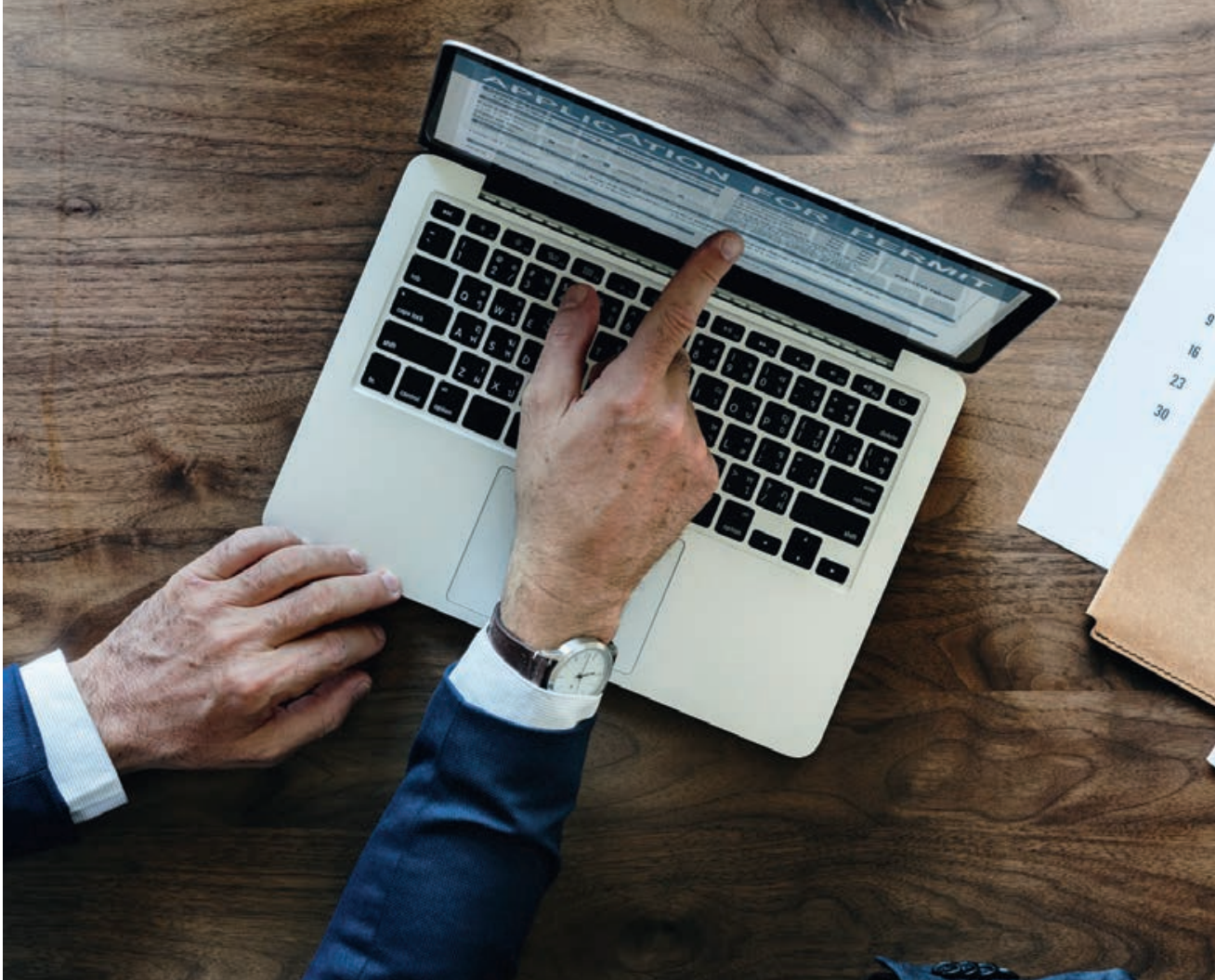

\section{/ / La Ley No 20.780 de 2014 -Reforma Tributaria- modificó tanto los impuestos que afectan a las empresas, como la manera de determinar varias de las rentas que deben declarar las personas naturales"}

den asumir la responsabilidad de capacitar a la ciudadanía en estos temas.

La tantas veces prometida intención del legislador de proponer normas tributarias simples ha sido superada por la incorporación de una normativa que apunta a un preciosismo en la determinación de las cifras, la complejidad de las normas que buscan evitar la elusión y la derogación de regímenes más simplificados, que se eliminan porque conllevan beneficios para los contribuyentes.

La complejidad de esta Reforma Tributaria requiere por parte del nuevo gobierno de normas especiales de implementación y puesta en marcha, que atenúen la presión que recae en los contadores, lo que dice relación con una normativa que limite al SII de cobrar multas e intereses sobre las diferencias de impuestos que se puedan generar. La misma debiera ser "permanente" cuando se modifique la legislación tributaria.

Si el propósito de los gobiernos es lograr una mayor recaudación u obtener resultados de políticas públicas en el corto plazo que pasen por un incentivo o un cambio a las materias tributarias, es fundamental que se conozcan los desafíos que estos cambios implican para el profesional que los implementa, ya que es parte fundamental del engranaje que provoca el cambio y hace viva la reforma para los contribuyentes, sean estos, personas naturales, Pymes, medianas y grandes empresas.

Que los gobiernos entiendan que la calidad de la formación profesional de los contadores va a redundar directamente en el éxito y desarrollo de la economía del país ha pasado a ser una exigencia de estos nuevos tiempos donde la inmediatez de los resultados de los cambios es esperada por toda la ciudadanía. 